\title{
Quality Assessment and Evaluation of Groundwater Potentials in Parts of Buruku and Gboko Local Government Area Councils in Benue State
}

\author{
Chukwuemeka Ngozi Ehirim*, Chioma Nwankwo \\ Geophysics Research Group, Department of Physics, University of Port Harcourt, Port Harcourt, Nigeria \\ Email: *emekabridgy@yahoo.com
}

How to cite this paper: Ehirim, C.N. and Nwankwo, C. (2016) Quality Assessment and Evaluation of Groundwater Potentials in Parts of Buruku and Gboko Local Government Area Councils in Benue State. International Journal of Geosciences, 7, 1064-1073.

http://dx.doi.org/10.4236/ijg.2016.79081

Received: June 15, 2016

Accepted: September 13, 2016

Published: September 16, 2016

Copyright $\odot 2016$ by authors and Scientific Research Publishing Inc. This work is licensed under the Creative Commons Attribution International License (CC BY 4.0).

http://creativecommons.org/licenses/by/4.0/ (c) (i) Open Access

\begin{abstract}
Hydraulic and layer parameters of groundwater aquifer have been evaluated in parts of Buruku and Gboko local government area councils, for the primary purpose of assessing quality and potential of groundwater in the areas. A total of 18 Vertical Electrical Sounding (VES) stations were occupied along traverse lines using the Schlumberger electrode configuration. The results revealed a characteristic QQA, $\mathrm{QHH}$ and $\mathrm{QH}$ type curves, with 6 - 7 geoelectric subsurface layers. The geoelectric layers are dominantly sandy with intercalations of shale at shallow depths in most stations. The aquiferous layers were delineated at the fourth and fifth geoelectric layers with average aquifer resistivity and depth of $420.56 \Omega \cdot \mathrm{m}$ and $69.1 \mathrm{~m}$, respectively. Groundwater flow is generally from the northeast to the southwest in line with the tectonics of the Benue trough. Two potential groundwater zones were delineated. These are the zone of poor quality water to the north (central) and east of the area of high potential and the zone of quality groundwater to the northeast, west and southwest of low potential. The study revealed that productive boreholes for excellent and sustainable yields were more viable in the northern (central) and eastern parts of the study area than in the northeast, west and southwest parts.
\end{abstract}

\section{Keywords}

Groundwater, Aquifer, Resistivity, Hydraulic Conductivity and Transmissivity

\section{Introduction}

Groundwater is one of the most valuable resources and main source of potable drinking 
water. It supplies fresh drinking water for over $95 \%$ of the world population. This is especially important in parts of the world that do not have ample surface water sources. Groundwater is stored in a geologic formation called aquifer. Aquifer is a water bearing layer which produces economically useful amount of water to springs and well. They are typically made up of gravel, sand, sandstone or fractured rock. The regional distribution on earth, however, varies and depends mainly on climatic conditions as well as the geology of the subsurface (Sophocleous, 2000; Alley and Leake, 2004) [1] [2].

The study area is located in parts of Buruku and Gboko local government council areas in Benue state (Figure 1). These areas lie within the lower Benue trough and is known to have challenges as regards to groundwater quality and, the hydraulic characteristics of the aquifer are not reliably known in other to assess groundwater potentials. The areas have large deposits of baryte and associated minerals at relatively shallow depth, which is extracted largely through artisanal mining. Unfortunately, these mineralization and lithological complexities greatly affects groundwater features in the area.

Groundwater in these areas is assessed through hand dug wells that rarely exceeds 20 $30 \mathrm{ft}$ in depth. These well waters are colourless and occasionally sparingly whitish, but tasty, which may be associated with the mineralogical and lithological characteristics of the formation. The majority of the local populace is farmers who depend solely on groundwater from the wells for drinking and domestic uses and therefore, requires potable drinking water for healthy living.

Geophysical methods provide a cost effective and non-invasive technique for groundwater studies (McNeill, 1994; Murty and Raghavan, 2002; Laust et al., 2005; Sundararajan et al., 2007) [3]-[6]. Groundwater quality assessment and potential evaluation from analysis of layer and hydraulic parameters (hydraulic conductivity, transmissivity, longitudinal conductance and electrical conductivity), derived from geoelectrical sounding measurements, have been made by several authors (Daniel et al., 2015;

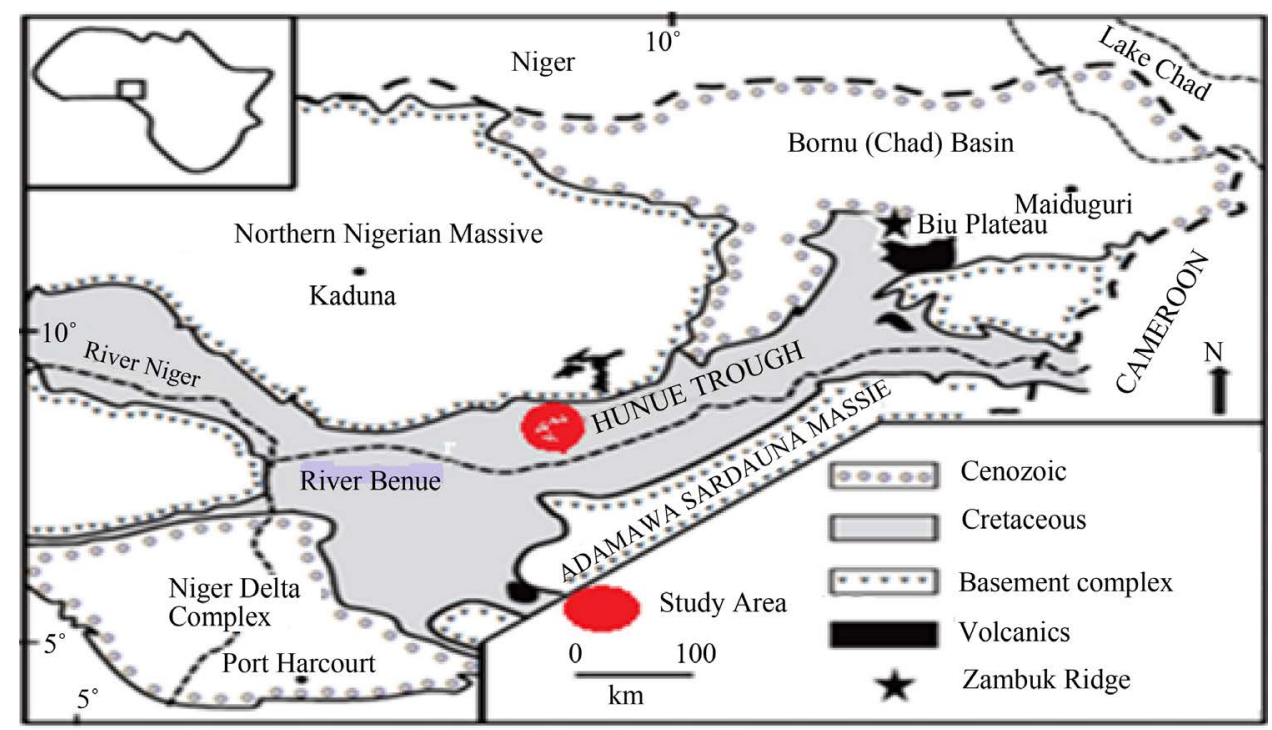

Figure 1. Location and Geologic map of the study area. 
Sankar, 2002; Reinhard and Daniel, 2002; Ehirim and Ebeniro, 2010; Ehirim and Nwankwo, 2010) [7]-[11].

This is based on the fact that aquifer resistivity is mostly influenced by porosity and fluid resistivity which depend on the salinity, a function of the total dissolved solids (TDS) in the permeating fluid. The amount of TDS determines the groundwater quality which can be adjudged from the aquifer resistivity (Ehirim et al., 2015) [12]. High and low aquifer resistivities are correlated with good and poor groundwater qualities, respectively. Also, the physical factors controlling electric current flow control the flow of water in porous media. As such, hydraulic and electrical conductivities are dependent on each other and governed by the same physical parameters of the rock materials. Thus, hydraulic parameters of the aquifer can be derived from surface geoelectric measurements obtained by the interpretation of vertical electrical sounding data (Salem, 1999) [13].

The vertical electrical sounding (VES) is a simple, low cost and high resolution geoelectrical technique. It has proved very useful in groundwater exploration and water quality evaluations because of the theoretical, operational and interpretational ease. Additionally, the control over depth of investigation, portability of the equipment, availability of wide range of simple and elegant interpretation techniques and related softwares make this technique be the explorer's choice for groundwater investigations.

The technique employs collinear arrays of four electrodes to measure subsurface potential distribution due to variations in conductivity within the earth's subsurface arising from induced electric current flow. The degree of this effect depends on the size, shape, location and bulk electrical resistivity of the subsurface layers. The result of VES measurement can be interpreted qualitatively as well as quantitatively. Quantitative interpretation is directly used in the evaluation of potentials and assessment of groundwater quality in this study.

The present study aims at assessing groundwater quality and evaluating aquifer hydraulic parameters to possibly delineate areas with quality groundwater and high aquifer potential using geoelectric method.

\section{Geology of the Study Area}

The study area is geologically underlain by the Eze-Aku shale Formation of Cretaceous age. Eze-Aku Formation consists of calcareous shales, micaceous fine to medium grained sandstones and shelly limestones (Figure 1), which plays significant role in the availability of both surface and groundwater (Kogbe et al., 1978) [14]. Locally, the shales grade into predominantly fluvial cross bedded sandstones of the Markurdi Formation, which is the main water bearing unit in the area. The formation is characterized by ferrugenized sandstones and to a lesser extent shale, quartz and calcite rocks in places (Offodile, 1976) [15].

Many mineralized baryte veins occupy E-W, NW-SE, and N-S fractures within the study area. Mineralization is structurally controlled and more or less confined to the limit of these faults (Chaanda et al., 2010 and Wright, 1976) [16] [17]. 
The study area is generally gently undulating and punctuated by few low hills and valleys at places. The vegetation is typically savannah with stunted trees and herbs. Recharge is principally by precipitation and most of the water goes into underground storage.

\section{Methodology}

A total of eighteen VES stations were occupied and mostly situated in areas of artisanal barite mining activity in the study area. The location of the VES stations was selected based on the surface assessment of the area in terms of space, topography and cultural barriers. In the majority of cases, the VES stations were separated $200 \mathrm{~m}$ apart, except were the effect of topography and cultural barriers could not be avoided in the survey.

Data was acquired using the Schlumberger electrode configuration with maximum half current electrode spacing $(\mathrm{AB} / 2)$ and half potential electrode spacing $(\mathrm{MN} / 2)$ of $400 \mathrm{~m}$ and $50 \mathrm{~m}$, respectively. The surveys were carried out using ABEM Terra metre SAS $1000 \mathrm{~B}$ resistivity meter.

The acquired resistance date was converted to apparent resistivity data using the appropriate geometric factor and subsequently, inverted using IP2WIN automated inversion software. This was necessary to allow for the interpretation of field data for saturated zones and estimation of hydraulic parameters in the study area.

The hydraulic conductivity $K$ was estimated using Equation (1);

$$
K=0.0538 e^{-0.0072\left(\rho_{a}\right)}
$$

Where $\rho_{a}$ equals to the apparent resistivity of the formation. This is a non-linear relationship between hydraulic conductivity $(K)$ and apparent resistivity $\left(\rho_{a}\right)$ by Singh (2005) [18].

The transmissivity $T$ is calculated from Equation (2) as;

$$
T=K b
$$

where $b$ is the aquifer thickness

Layer parameters and the calculated hydraulic parameters $(K, T, S$ and $\sigma$ ) from VES results were used to generate property maps using surfur 10 software for the purposes of assessing quality and evaluating groundwater potentials in the study area.

\section{Result Presentation}

The modeled curves are of the QQA, QHH and QH type curves with 6 - 7 geoelectric layers. Each of the geoelectric layers differ significantly with respect to their resistivity and depth. The resistivities vary from $41.5 \Omega \cdot \mathrm{m}$ to $2056.0 \Omega \cdot \mathrm{m}$ with depths of $1.85 \mathrm{~m}$ to $150.0 \mathrm{~m}$ and thicknesses of $1.85 \mathrm{~m}$ to $77.1 \mathrm{~m}$ in the study area.

The aquiferous layers were delineated at the fourth and fifth geoelectric layers. The aquifer resistivities vary from $111.0 \Omega \cdot \mathrm{m}$ to $932.0 \Omega \cdot \mathrm{m}$ with an average value of 420.56 $\Omega \cdot \mathrm{m}$, depth range of $53.1 \mathrm{~m}$ to $72.9 \mathrm{~m}$ with an average depth of $69.1 \mathrm{~m}$ and thickness range of $36.50 \mathrm{~m}$ to $41.40 \mathrm{~m}$ with an average thickness of $38.83 \mathrm{~m}$ in the study area (Table 1). The interpreted geoelectric sections for the eighteen VES stations are shown 
in Figure 2. Results show that the layers are dominantly sandy with intercalations of shale at shallow depths. The aquifers are unconfined with no evidence of confined or semi confined structures in the study area.

Contour maps of five aquifer properties are shown in Figures 3-7. The maps show the spatial distribution of these properties in the area. This is an indication of the variable nature of groundwater aquifers in the study area. This variability makes accurately describing the hydraulic properties of an aquifer difficult. The resistivity map (Figure 3) show low aquifer resistivity distribution to north (central) and eastern part of the area and medium to high values to north east, west and south west. The resistivity map revealed a resistivity distribution in the area associated with groundwater quality. Medium to high resistivity distributions is interpreted as probably indicative of the presence of quality groundwater, while low resistivity distribution is interpreted as poor quality groundwater.

Depth contour map (Figure 4) show low aquifer depths to the northeast and medium to high aquifer depths to the east, west and south west. The map also show a

Table 1. Summary of aquifer properties for all the VES stations.

\begin{tabular}{|c|c|c|c|c|c|c|c|}
\hline VES Nos. & $\begin{array}{c}\text { Resistivity } \\
\quad \rho(\Omega \mathrm{m})\end{array}$ & $\begin{array}{l}\text { Aquifer } \\
\text { Depth } \\
\text { (m) }\end{array}$ & $\begin{array}{l}\text { Thickness } \\
\text { (m) }\end{array}$ & $\begin{array}{c}\text { Electrical } \\
\text { Conductivity } \\
(\Omega \mathrm{m})^{-1} \times 10^{-3}\end{array}$ & $\begin{array}{l}\text { Longitudinal } \\
\text { Conductance } \\
S(\Omega)^{-1} \times 10^{-2}\end{array}$ & $\begin{array}{c}\text { Hydraulic } \\
\text { Conductivity } \\
\text { (m/day) }\end{array}$ & $\begin{array}{c}\text { Transmissivity } \\
\left(\mathrm{m}^{2} / \text { day }\right)\end{array}$ \\
\hline Line 1 & 265.0 & 68.50 & 39.00 & 3.77 & 14.7 & 66.50 & 2593.50 \\
\hline Line 2 & 213.0 & 67.90 & 37.60 & 4.69 & 17.70 & 1002.24 & $37,684.22$ \\
\hline Line 3 & 508.0 & 67.30 & 36.50 & 1.97 & 7.20 & 120.96 & 4415.04 \\
\hline Line 4 & 580.0 & 66.20 & 36.50 & 1.72 & 6.30 & 71.37 & 2605.01 \\
\hline Line 5 & 158.0 & 53.10 & 37.00 & 6.33 & 23.40 & 1486.08 & $54,984.96$ \\
\hline Line 6 & 161.0 & 69.10 & 37.80 & 6.21 & 23.50 & 1451.52 & $54,867.46$ \\
\hline Line 7 & 140.0 & 70.40 & 39.20 & 7.14 & 28.00 & 1693.44 & $66,382.85$ \\
\hline Line 8 & 132.0 & 70.40 & 38.50 & 7.58 & 29.20 & 1797.12 & $69,189.12$ \\
\hline Line 9 & 132.0 & 69.10 & 38.20 & 7.58 & 28.90 & 1797.12 & $68,649.98$ \\
\hline Line 10 & 140.0 & 70.40 & 37.90 & 7.14 & 27.10 & 1693.44 & $64,181.38$ \\
\hline Line 11 & 839.0 & 71.60 & 40.30 & 1.19 & 4.80 & 11.06 & 445.72 \\
\hline Line 12 & 824.0 & 72.90 & 40.40 & 1.21 & 4.90 & 12.32 & 497.73 \\
\hline Line 13 & 111.0 & 69.60 & 38.80 & 9.00 & 35.00 & 2090.88 & $81,126.14$ \\
\hline Line 14 & 140.0 & 71.60 & 40.30 & 7.14 & 28.80 & 1693.44 & $68,245.63$ \\
\hline Line 15 & 755.0 & 71.60 & 39.70 & 1.32 & 5.30 & 20.22 & 802.73 \\
\hline Line 16 & 932.0 & 72.90 & 41.40 & 1.07 & 4.40 & 5.66 & 234.32 \\
\hline Line 17 & 656.0 & 70.40 & 40.10 & 1.52 & 6.10 & 41.30 & 1656.13 \\
\hline Line 18 & 884.0 & 71.60 & 39.70 & 1.13 & 4.50 & 8.00 & 317.6 \\
\hline
\end{tabular}




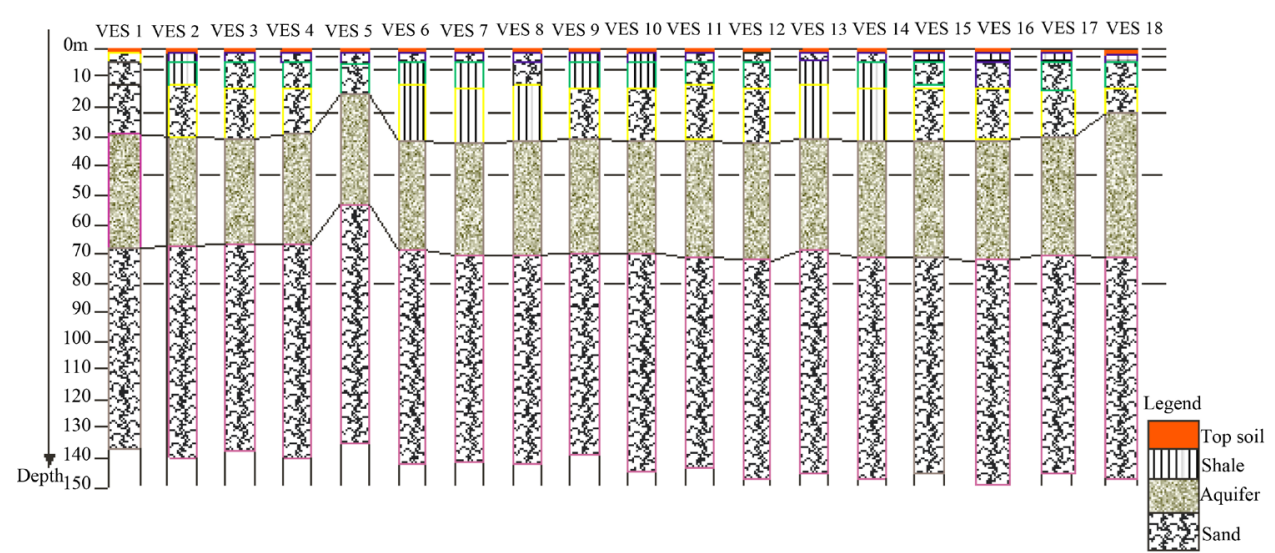

Figure 2. Interpreted geoelectric sections for the eighteen VES points.

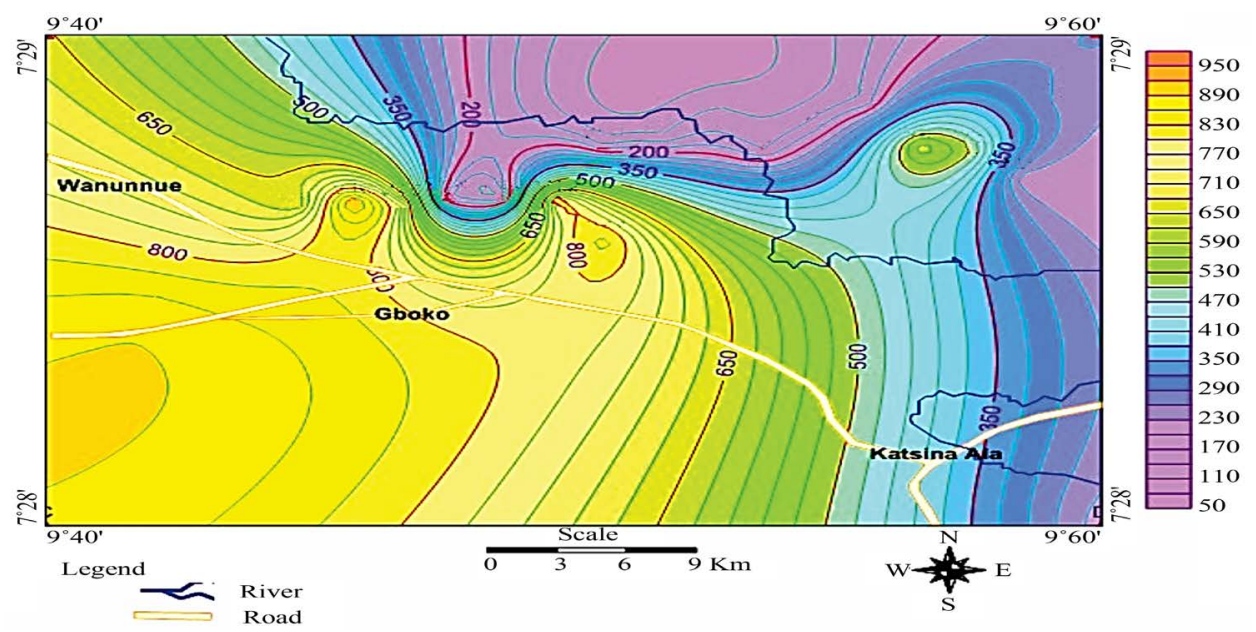

Figure 3. Resistivity contour map of the aquiferous zones in the study area.

NE-SW aquifer depth gradient, which probably suggests that groundwater flows from the NE to the SW of the area. Groundwater to the SW area of the study is suspected to be of high quality than the NE due to increasing depths of the aquifers in the study area. The longitudinal conductance map (Figure 5) shows low aquifer conductance to the north east, west and south west and medium to high conductance values to the north (central) and east of the area. Low conductance values is interpreted as low aquifer protective capacity due little or no overlying shale bed and medium to high conductance as high aquifer protective capacity due to thick overlying shale bed in the study area.

The hydraulic conductivity map (Figure 6) show low hydraulic conductivities to north east, west and south west, while medium to high conductivities were delineated to the north (central) and south east. Low conductivity values are interpreted as low permeable aquifers, while high conductivities are interpreted as high permeable aquifers in the study area.

The transmissivity contour map (Figure 7) show low transmissivity values to the north east, west and south west, while medium to high transmissivity were delineated to the 


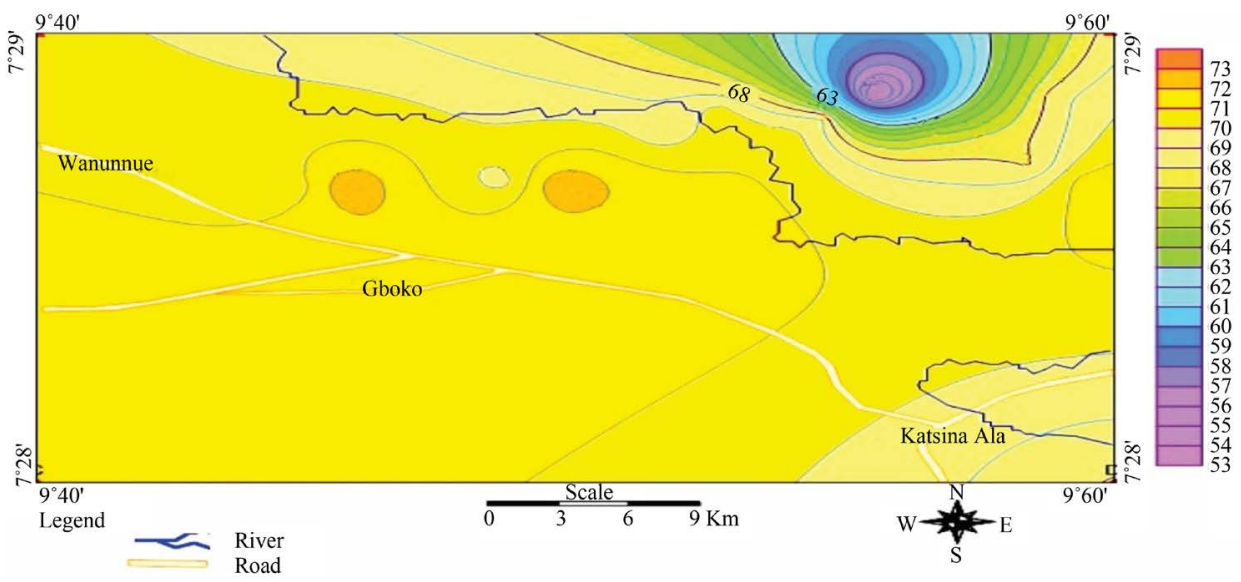

Figure 4. Depth contour map of the aquiferous zones in the study area.

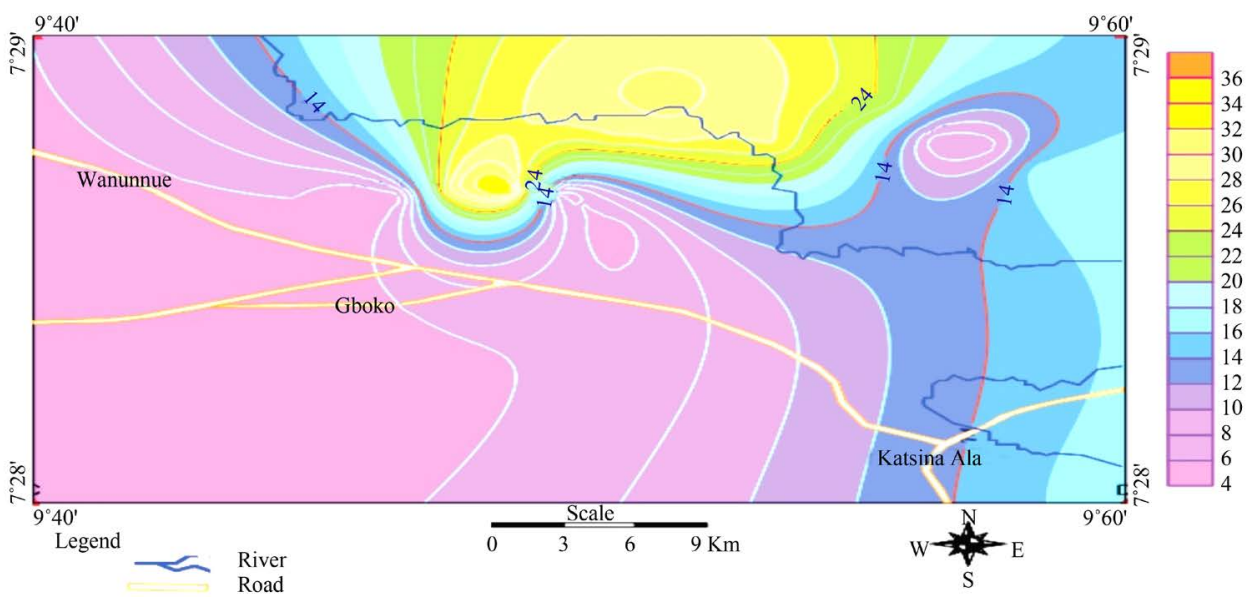

Figure 5. The Longitudinal conductance map of the aquiferous zones of the study area.

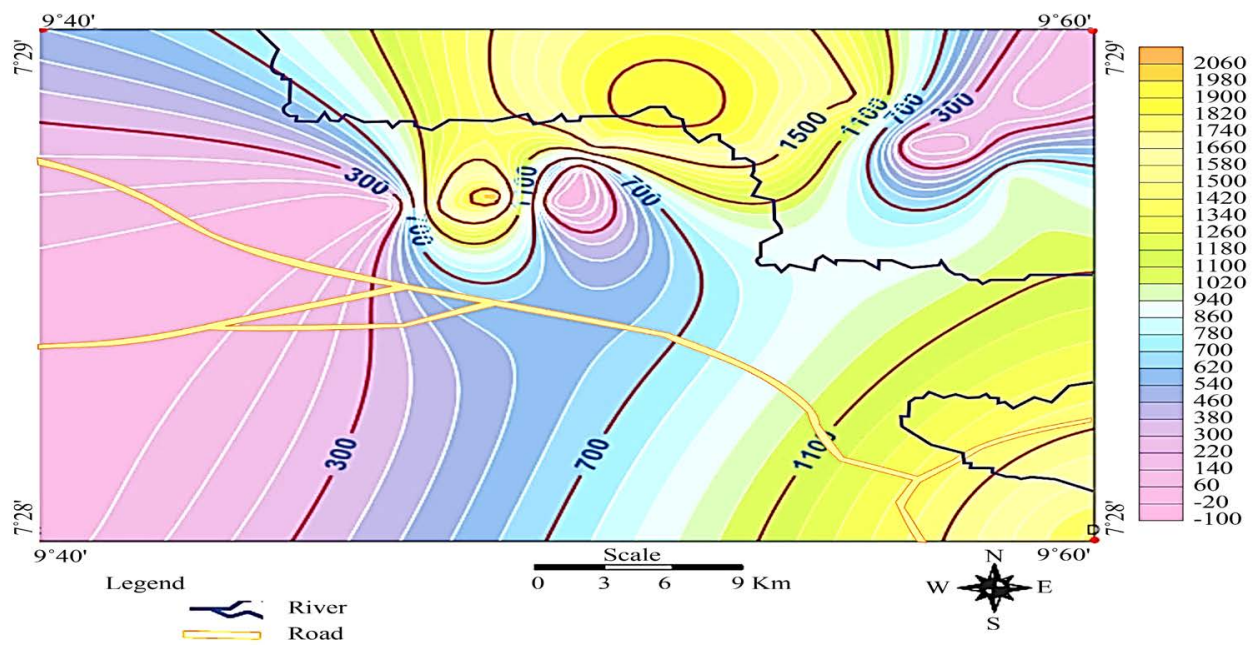

Figure 6. Hydraulic conductivity map of the aquiferous zones in the study area.

north (central) and south east. Low transmissivity values are interpreted as low yield aquifers, while high transmissivities are interpreted as high yield aquifers in the study area. 


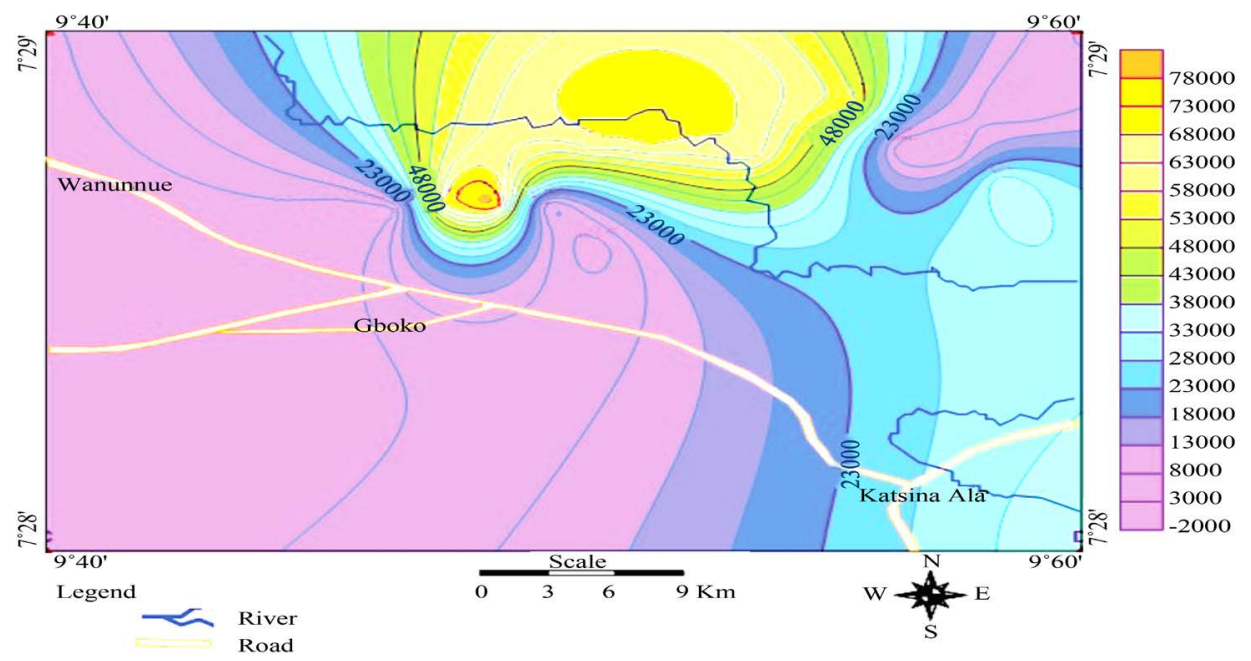

Figure 7. Transmissivity map of the aquiferous zones in the study area.

\section{Discussion of Result}

Hydraulic and layer parameters of groundwater aquifer have been evaluated in parts of Buruku and Gboko local government area councils, for the primary purpose of assessing quality and potential of groundwater resources. The result of study show characteristics QQA, QHH and QH type curves with 6 - 7 geoelectric subsurface layers. The geoelectric layers are dominantly sandy with intercalations of shale at shallow depths. The aquiferous layers were delineated at the fourth and fifth geoelectric layers with average aquifer resistivity and depth of $420.56 \Omega \cdot \mathrm{m}$ and $69.1 \mathrm{~m}$, respectively, unconfined and with no evidence of confined or semi confined structures in the study area.

The contour maps of layer and hydraulic parameters of resistivity, depth, longitudinal conductance, hydraulic conductivity and transmissivity derived from geoelectrical measurements were used to assess quality and potential of groundwater in the area. The maps revealed the anomalous distribution of these parameters in the study area, which are reflections of the saturation, mineralogy and lithological variability of the aquifer system.

Low resistivity distribution to the north (central) and eastern parts of the area is related to poor quality groundwater probably due to the effect of mineralization. Mineralization has the tendency to elevate TDS concentrations, which could lower the resistivity of groundwater. Medium to high resistivity distributions to the north east, west and southwest are correlated with saturated aquifer and thus high quality groundwater (Daniel et al., 2015; Reinhard and Daniel, 2002) [7] [9].

The poor quality groundwater zones (low resistivity), probably due to mineralization, are associated with high longitudinal conductance, hydraulic conductivity and transmissivities in the north (central) and east of the area. These are glaring indications that the aquiferous layer in these zones is well protected from surface induced contaminant seepage due to impermeable overlying shale bed, highly permeable and of excellent yield. These results however, are in contrast to the high quality groundwater zones (medium to high resistivity zones), which correlates with low longitudinal conductance, 
hydraulic conductivity and transmissivity in the northeast, west and southwest of study area. This suggests that the aquiferous layer in these zones is poorly protected due to thin or absence of overlying shale bed. The aquiferous layer in these zones is hydrologically in contact with the surface and therefore prone to surface induced contaminations, less permeable and of poor yield (Ehirim and Nwankwo, 2010) [11].

The aquifer depth map show a low in the northeast and medium to high to the East, west and south west of the study area. A generally NE-SW aquifer depth gradient was delineated, which probably suggests that groundwater flows from the NE to the SW of the study area. This revelation however, is in line with the trend of the lower Benue trough which validates our results (Wright, 1976) [17].

Generally, two potential groundwater zones were mapped. The zones of poor quality water to the north (central) and east of high potential and the zone of high quality groundwater to the northeast, west and southwest of low potential.

Explorationist should therefore, strike the balance between the water needs of the people in terms of potential availability and the quality of the groundwater in the study area.

\section{Conclusions}

Groundwater features in the study area are better in the northern (central) and eastern parts than in the northeast, west and the southwest parts of the study area. Groundwater flow is generally from the northeast to the southwest in line with the tectonics of the Benue trough. Two potential groundwater zones are delineated. These are the zone of poor quality water to the north (central) and east of the area of high potential and the zone of quality groundwater to the northeast, west and southwest of low potential.

Based on these revelations, potable boreholes for groundwater development is more viable in the northern (central) and eastern parts of the study area than in the northeast, west and southwest of the study area. This should be further investigated since there are no existing boreholes in the study area to correlate the results of this research.

\section{References}

[1] Sophocleous, M. (2000) From Safe Yield to Sustainable Development of Water ResourcesThe Kansas Experience. Journal of Hydrology, 235, 27-43. http://dx.doi.org/10.1016/S0022-1694(00)00263-8

[2] Alley, W.M. and Leake, S.A. (2004) The Journey from Safe Yield to Sustainability. Ground Water, 42, 12-16. http://dx.doi.org/10.1111/j.1745-6584.2004.tb02446.x

[3] McNeillJ, D. (1991) Advances in Electromagnetic Methods for Groundwater Studies. Geoexploration, 27, 65-80. http://dx.doi.org/10.1016/0016-7142(91)90015-5

[4] Murty, B. and Raghavan, V. (2002) The Gravity Method in Groundwater Exploration in Crystalline Rocks: A Study in the Peninsular Granitic Region of Hyderabad, India. Hydrogeology Journal, 10, 307-321. http://dx.doi.org/10.1007/s10040-001-0184-2

[5] Pedersen, L.B., Bastani, M. and Dynesius, L. (2005) Groundwater Exploration Using Combined Controlled-Source and Radio Magnetotelluric Techniques. Geophysics, 70, G8-G15. http://dx.doi.org/10.1190/1.1852774 
[6] Sundararajan, N., Nandakumar, G., Narsimha Chary, M., Ramam, K. and Srinivasan, Y. (2007) VES and VLF-An Application to Groundwater Exploration, Khammam, India. The Leading Edge, 26, 708-716. http://dx.doi.org/10.1190/1.2748489

[7] Daniel, N.O., Johnson, C.I. and Nyakno, J.G. (2015) Geophysical Assessment of Potential Hydrological Units in Hydrologically Challenged Geomaterials of Makurdi, Benue State, Nigeria. International Journal of Physical Sciences, 10, 479-489.

[8] Sankar, K. (2002) Evaluation of Groundwater Potential Zones Using Remote Sensing Data in Upper Vaigai River Basin, Tamil Nadu, India. Journal of the Indian Society of Remote Sensing, 30, 119-129. http://dx.doi.org/10.1007/BF02990644

[9] Reinhard, K.F. and Daniel, W.U. (2002) The Use of Geoelectrics and Test Wells for the Assessment of Groundwater Quality of a Coastal Industrial Site. Journal of Applied Geophysics, 50, 261-278. http://dx.doi.org/10.1016/S0926-9851(02)00146-5

[10] Ehirim, C.N. and Ebeniro, J.O. (2010) Evaluation of aquifer Characteristics and Groundwater Potentials in Awka, Southeast Nigeria, Using Vertical Electrical Sounding. Asian Journal of Earth Sciences, 3, 73-81. http://dx.doi.org/10.3923/ajes.2010.73.81

[11] Ehirim, C.N and Nwankwo, C.N. (2010) Evaluation of Aquifer Characteristics and Groundwater Quality Using Geoelectric Method in Choba, Port Harcourt. Archives of Applied Science Research, 2, 396-403.

[12] Ehirim, C.N., Adizua, O.F. and Okorie, I.P.C. (2015) Geoelectric Characterization of matured Petroleum Hydrocarbon Impacted soil in Port Harcourt, Nigeria. Asian Journal of Earth Sciences, 9, 9-15. http://dx.doi.org/10.3923/ajes.2016.9.15

[13] Salem, H.S. (1999) Determination of Fluid Transmissivity and Electric Transverse Resistance for shallow Aquifers and deep reservoirs from Surface and Well-Log Electric Measurements. Hydrology and Earth System Sciences, 3, 421-427. http://dx.doi.org/10.5194/hess-3-421-1999

[14] Kogbe, C.A., Torkashi, A., Osijuk, D. and Wozney, D.E. (1978) Geology of Makurdi in the Middle Benue Valley Nigeria. Occasional Publication of Department of Geology, Ahmadu Bello University, Zaria.

[15] Offodile, M.E. (1976) Review of the geology of the Cretaceous Benue Valley. In: Kogbe, C.A., Ed., Geology of Nigeria, Elizabethan Publishing Coy, Lagos, 319-330.

[16] Chaanda, M.S., Obaje, N.G., Moumouni, A., Goki, N.G. and Law, U.A. (2010) Environmental Impact of Artisanal Mining of Barytes in Azara Area, Middle Benue Trough Nigeria. Journal of Earth Sciences, 4, 38-42.

[17] Wright, A.E. (1976) Review of the Origin and Evolution of the Benue Trough in Nigeria. Department of Earth Sciences, Open University, Milton Keynes.

[18] Singh, K.P. (2005) Nonlinear Estimation of Aquifer Parameters from Surficial Resistivity Measurements. Hydrology and Earth System Sciences, 2, 917-993.

http://dx.doi.org/10.5194/hessd-2-917-2005 
Submit or recommend next manuscript to SCIRP and we will provide best service for you:

Accepting pre-submission inquiries through Email, Facebook, LinkedIn, Twitter, etc. A wide selection of journals (inclusive of 9 subjects, more than 200 journals)

Providing 24-hour high-quality service

User-friendly online submission system

Fair and swift peer-review system

Efficient typesetting and proofreading procedure

Display of the result of downloads and visits, as well as the number of cited articles

Maximum dissemination of your research work

Submit your manuscript at: http://papersubmission.scirp.org/ 